\title{
Uric Acid Crystal Measurement
}

National Cancer Institute

\section{Source}

National Cancer Institute. Uric Acid Crystal Measurement. NCI Thesaurus. Code C74684.

The determination of the amount of uric acid crystals present in a sample. 